\title{
Temporal patterns in coral assemblages on the Great Barrier Reef from local to large spatial scales
}

\author{
R. Ninio ${ }^{1, *}$, M. Meekan ${ }^{1,2}$, T. Done ${ }^{1}$, H. Sweatman ${ }^{1}$ \\ ${ }^{1}$ The Australian Institute of Marine Science, PMB 3, Townsville M.C., Queensland 4810, Australia \\ ${ }^{2}$ The Australian Institute of Marine Science, PO Box 264, Dampier, Western Australia 6713, Australia
}

\begin{abstract}
ABSIRACT: From 1992 to 1997 changes in cover of hard and soft corals and macro-algae were monitored using annual video transect surveys on the northeast flank of up to 52 reefs along most of the Great Barrier Reef (GBR). Trends in cover of hard corals, algae and soft corals were usually consistent among clusters of adjacent or nearby reefs. This consistency probably reflected the spatial scales of the effect of episodic disturbances caused by cyclones or crown-of-thorns starfish Acanthaster planci. Hence, our comprehensive monitoring of a single habitat provided an effective indicator of the status and trends on adjacent reefs. Moreover, we observed broad-scale patterns of increase and decline in coral cover that suggest that a 'patchwork mosaic' null model is a useful concept at scales of whole reefs and regions. At a large spatial scale (up to $10^{\circ}$ of latitude), cover of hard corals within the NE slope habitat averaged $29 \%( \pm 12.4$ standard deviation) and increased by $1.7 \%( \pm 6.5)$ over 5 yr of surveys. Cover of soft corals and algae remained constant and averaged $14 \%( \pm 12.4)$ and $41 \%( \pm 16.6)$ respectively. Inner shelf, mid-shelf and outer shelf reefs in a 'recovery' phase increased their cover of hard coral at average annual rates of $2.6 \%( \pm 3.0), 3.9 \%( \pm 4.1)$ and $4.3 \%( \pm 4.5)$ respectively. Year-to-year changes in cover of soft corals were typically smaller and less variable than changes in cover of hard corals or algae. There was no evidence of any shift to alternative stable states of assemblage composition.
\end{abstract}

KEY WORDS: Coral · Long term - Temporal - Great Barrier Reef - Spatial

\section{INTRODUCTION}

The benthic assemblages of coral reefs are dynamic and subject to disturbance on a great variety of spatial and temporal scales (Dollar 1982, Dollar \& Tribble 1993, Massel \& Done 1993, Edmunds \& Bruno 1996, Done 1997, Connell et al. 1998). Disturbances (e.g. cyclones, Bythell et al. 1993; crown-of-thorns starfish (COTS) Acanthaster planci, Moran 1986; bleaching, Glynn 1993) often result in a loss of cover of hard corals over areas of hectares and greater. Coral loss may be followed by an increase in soft corals (Benayahu \& Loya 1981, Endean et al. 1988) or by benthic algae (Done 1992a, Hughes 1994), although sometimes fleshy biomass of any kind is kept at low levels by scraping of fishes and/or invertebrates so that the reef appears 'bare'. Alternate assemblages or 'bare' periods

\footnotetext{
•E-mail: r.ninio@aims.gov.au
}

may represent a transient stage that will, within a few years, be replaced by coralline algae and reef-building hard corals (Done et al. 1988, Done 1992a, b, Dollar \& Tribble 1993). Alternatively, some studies suggest that this phase in community composition may represent a persistent state, particularly in situations where disturbances are chronic or the recovery of hard corals has been affected by human activities (Hughes 1994, Hunter \& Evans 1995).

Most studies that have followed trends in assemblage structure and abundance have resolved temporal patterns at relatively small spatial scales (Connell 1997). The longest running studies are restricted to sites in a few habitats at only 1 or 2 reefs, notably Heron Island on the southern Great Barrier Reef (GBR) and Jamaica in the Caribbean. The inability of sampling programs to resolve spatial and temporal patterns simultaneously means that we lack the context to determine the generality of results obtained from pre- 
vious studies. At scales larger than a single coral reef, we are often unable to answer the most salient question asked by those responsible for management, which is 'will assemblages of hard corals recover after a disturbance and, if so, how long will it take?'

With the results of a long-term and large-scale monitoring study on the GBR now becoming available (e.g. Sweatman et al. 1998), we are now able to address this important question on the basis of recent trends. Here, we report the results from the first $5 \mathrm{yr}$ of sampling of the Long Term Monitoring Program (LTMP) conducted by the Australian Institute of Marine Science (AIMS). This ongoing program, which began in 1992, is the largest quantitative monitoring study of coral reefs in the world (Sweatman et al. 1998). The LTMP examines the rates of change in cover of benthic assemblages within a single coral reef habitat at a hierarchy of spatial scales ranging from single transects $(50 \mathrm{~m})$, to most of the GBR (from 14 to $24^{\circ} \mathrm{S}$ ). We define the spatial extent of changes in cover caused by different types of disturbance and the response and recovery of assemblages over a period of $5 \mathrm{yr}$ at spatial scales that span the major variations in the composition of coral assemblages on the GBR (Done 1982). While we do not examine the underlying demographic processes such as recruitment and survivorship that drive temporal patterns, we do provide the first record of the relative abundance and spatial extent of transitions to 'bare' substratum or assemblages other than hard corals and offer an opinion on the likely duration of these alternate states.

\section{METHODS}

The LTMP samples up to 52 reefs annually. Sampling is stratified by latitude and position of reefs on the continental shelf in order to accommodate the differences in the composition and richness of coral assemblages that occur at these scales (Done 1982). Here, we describe the results of annual surveys during the 5 yr 1992-1997.

Study reefs were located in 6 sectors, from the Cooktown-Lizard sector in the north of the GBR $\left(14^{\circ} \mathrm{S}\right)$ to the Capricorn-Bunker sector $\left(24^{\circ} \mathrm{S}\right)$ in the south (Fig. 1). Within each of these sectors, sampling was further stratified by position on the continental shelf: 'inner shelf' reefs - those closest to the coast; 'outer shelf reefs' - those bordering the edge of the continental slope; and 'mid-shelf reefs' - those equidistant between outer and inner shelf reefs (Fig. 1). Hereafter, each of these 3 positions on the shelf within a sector is referred to as a 'locality'. In 4 of the sectors, we censused 3 to 4 inner, mid-and outer shelf reefs. In the fifth (the Swains sector) which is remote $(150 \mathrm{~km})$ from coastal environments, we categorised the sample as 3 outer shelf and 6 mid-shelf reefs. In the sixth (the Capricorn-Bunker sector), which lies in open water $100 \mathrm{~km}$ to the south of the major reef matrix of the GBR, all reefs censused were categorised as outer shelf'.

The total number of reefs sampled each year and their distribution by locality are shown in Table 1. On each survey reef, 3 permanent sites were established

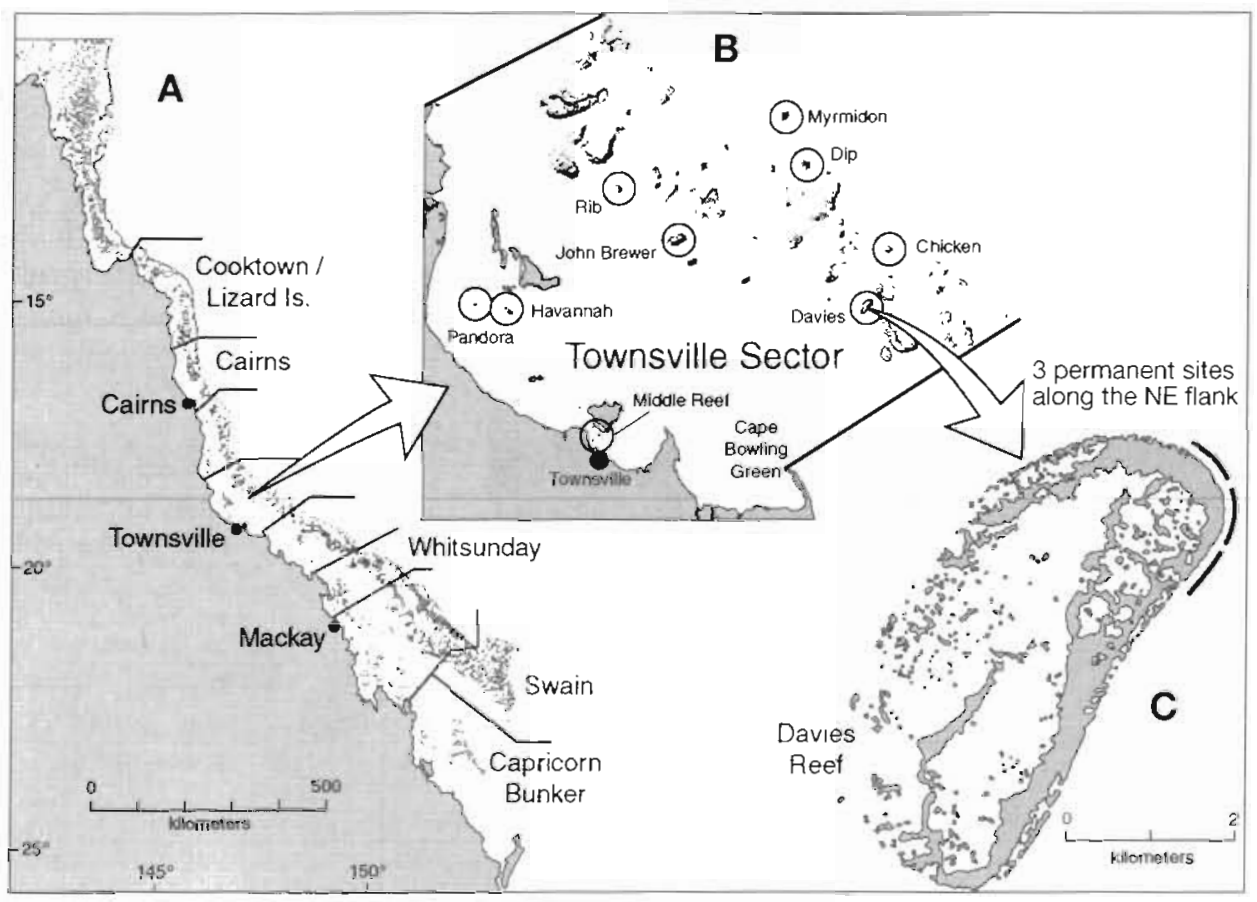

Fig. 1. (A) Sectors sampled by the study. (B) Cross-shelf distribution of sample reefs (circled) in Townsville sectorinner: Havannah, Pandora and Middle Reef; mid-: Rib, John Brewer and Davies; outer: Myrmidon, Dip and Chicken. (C) Distribution of sites on a single reef 
Table 1. Number of reefs sampled in each sector-shelf locality during summer field seasons by the Long Term. Monitoring Program

\begin{tabular}{|lllllll|}
\hline Sector & Shelf & \multicolumn{5}{c}{ Season } \\
& & $1992 / 3$ & $1993 / 4$ & $1994 / 5$ & $1995 / 6$ & $1996 / 7$ \\
\hline Cooktown- & Inner & 2 & 1 & 3 & 3 & 3 \\
Lizard. & Mid & 1 & 3 & 3 & 3 & 3 \\
& Outer & 2 & 2 & 3 & 3 & 3 \\
Cairns & Inner & 2 & 2 & 3 & 3 & 3 \\
& Mid & 3 & 3 & 4 & 4 & 3 \\
& Outer & 1 & 1 & 3 & 3 & 3 \\
Townsville & Inner & 2 & 1 & 2 & 2 & 2 \\
& Mid & 2 & 2 & 3 & 2 & 3 \\
Whitsundays & Outer & 2 & 2 & 3 & 3 & 3 \\
& Inner & 2 & 2 & 3 & 3 & 3 \\
Mid & 1 & 3 & 4 & 4 & 4 \\
Swains & Outer & & 2 & 3 & 3 & 3 \\
Capricorn- & Mid & 5 & 4 & 6 & 6 & 5 \\
Bunkers & Outer & & 2 & 2 & 3 & 2 \\
Total & & 4 & 2 & 3 & 5 & 4 \\
& & & & & & \\
& & 29 & 32 & 48 & 51 & 47 \\
\hline
\end{tabular}

on the northeastern flank (Fig. 1C). Within each site, we censused five $50 \mathrm{~m}$ transects arranged along the depth contour at 6 to $9 \mathrm{~m}$ depth. The transects were separated by approximately $10 \mathrm{~m}$. Each transect was marked at each end with a steel stake and at $10 \mathrm{~m}$ intervals with a steel pin driven into the reef. A tape measure was stretched between the pins on each census occasion. A Hi-8 Video was used to record the benthos in a $25 \mathrm{~cm}$ wide path along each transect. The camera was pointed downwards at a range of 25 to $30 \mathrm{~cm}$ above the bottom.

Percentage cover of the various benthic organisms was estimated from the videotape using a point sampling technique modified after Carleton \& Done (1995). Approximately 200 points were sampled per transect to as high a taxonomic resolution as possible (i.e. most coral genera and many distinctive species were recognised, as well as broader growth form categories). The videotape was paused at regular time intervals and a record made of the benthic categories lying beneath each of 5 points on the monitor screen (corners and centre of a square acetate overlay on the monitor screen; see Christie et al. 1996).

Data analysis. For the present analysis, the point records were aggregated into the following categories: hard coral, soft coral, turf algae, sand, rubble, macroalgae, coralline algae, sponge and 'other'. Hard corals were also classified into the life-forms of tabulate Acropora, non-tabulate Acropora and other coral. Estimates of percentage cover were adjusted to account for sand, so that they did not include benthic habitats that could not be colonised by sessile organisms. The categories macro-algae and turf algae were pooled for analysis.

Temporal trends in cover of hard coral, soft coral and algae were analysed using mixed linear models (PROC MIXED, SAS V6). Prior to analysis, cover estimates were logit transformed (McCullagh \& Nelder 1989). Linear models were used to fit quadratic curves to the transformed data sets and the significance of linear and quadratic components of the models then tested (see also Sweatman et al. 1998). These analyses identified and described significant trends in cover over time within each locality. The models included an autoregressive covariance structure to account for the similarities between successive measurements from the same transect through time. In localities where significant changes in cover of hard corals were found, trends in cover of the major components of the hard coral assemblage were also analysed using mixed linear models.

\section{RESULTS}

\section{Changes in cover of benthic assemblages at the scale of the GBR}

Benthic assemblages were dominated by hard corals, soft corals and turfing algae (Fig. 2). Cover of hard corals averaged $29 \%( \pm 12.4 \mathrm{SD})$, while cover of soft coral and algae averaged $14 \%( \pm 12.4)$ and $41 \%$ $( \pm 16.6)$ respectively during the $5 \mathrm{yr}$ of the study. Over the 5 yr period of the study, average cover of hard coral increased at an annual rate of $1.7 \%( \pm 6.5)$ and this rate

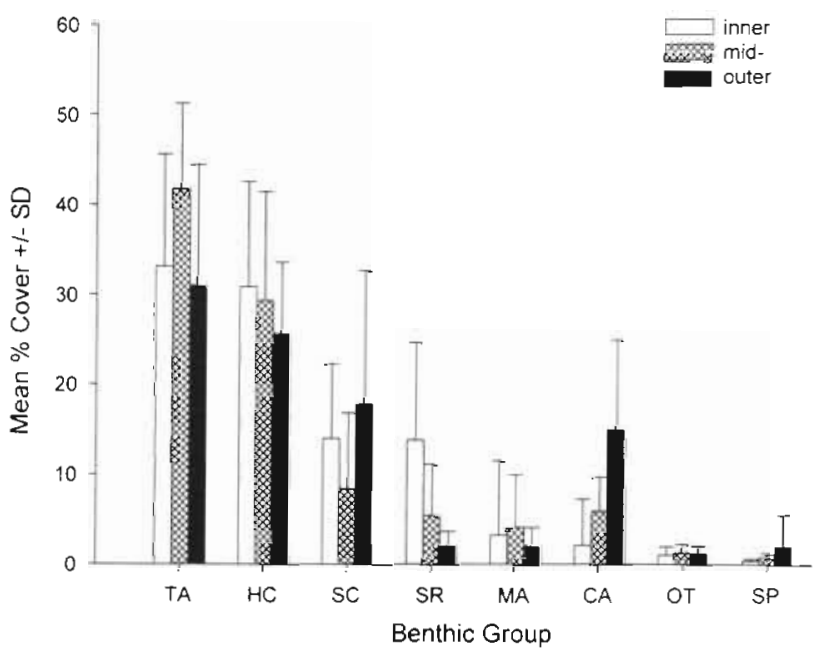

Fig. 2. Mean percentage cover ( \pm standard deviation) of benthic groups on the northeast flanks of reefs on the GBR during the $5 \mathrm{yr}$ of the survey. TA: turfing algae, HC: hard coral, SC: soft coral, SR: sand and rubble, MA: macro-algae, CA: coralline algae, OT: other, SP: sponge 


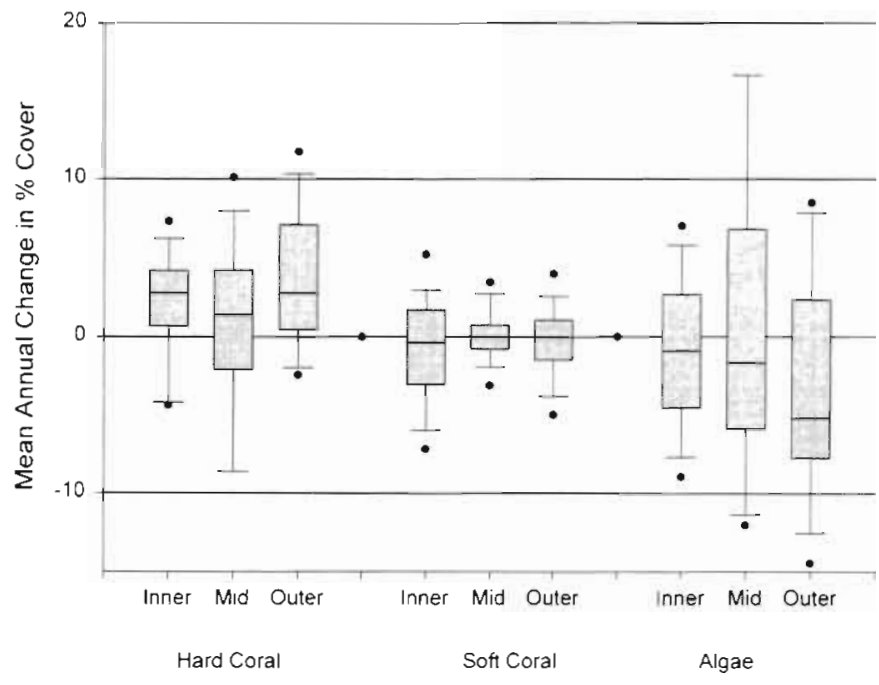

Fig. 3. Box-plots showing mean annual changes in percentage cover of hard corals, soft corals and algae on the northeast flanks of all reefs on the inner, mid- and outer shelf of the GBR (data sets pooled among sectors). Lower point, error bar and bound of the box show the 5 th, 10 th and 25 th percentiles of the data respectively. Solid bar within the box shows the median. Upper bound of the box, error bar and upper point show the 75th, 90th and 95th percentiles of the data respectively

of increase was significantly different from zero $(\mathrm{df}=$ $141, t=3.1, p=0.002$ ). Changes on a single reef in any one year ranged from a loss of $25 \%$ to an increase of $18 \%$ in cover of hard corals. There was no relationship between annual change in hard coral cover on a reef and cover in the previous year (regression analysis, $\mathrm{p}=$ 0.874). Furthermore there was no consistent relationship between annual changes in hard coral cover on a reef and cover of soft corals, macro-algae or sponges on that reef in the previous year $\left(\mathrm{r}^{2}<0.32\right.$ for all regression analyses)

The range of annual changes in cover of soft corals was much smaller than that of hard coral. Overall, mean changes in cover of soft corals and algae did not differ from zero (soft corals $-0.22 \pm 3 \%$, df $=$ 1.41, $t=-0.88, \mathrm{p}=0.38$; algae $-0.97 \pm$ $9.4 \%, \mathrm{df}=141, t=-1.22, \mathrm{p}=0.22$ )

Annual changes in cover of hard corals, soft corals and algae on inner, mid-and outer shelf reefs are summarised in Fig. 3. For hard corals, the greatest range in changes in cover occurred on the midshelf reefs, where the variation in annual change was approximately twice that of inner and outer shelf reefs. This was largely due to declines in cover on a small number of reefs exposed to cyclones or outbreaks of crown-of-thorns starfish.
In contrast to patterns in cover of hard corals, changes in cover of soft corals were uniform across inner, mid- and outer shelf reefs. The distributions of changes were relatively narrow when compared to those of hard corals and algae (Fig. 3). Algae, like hard corals, had a narrower distribution of changes on inner reefs than on mid-and outer shelf reefs (Fig. 3).

\section{Changes in cover of benthic assemblages among localities}

There were notable differences in changes in cover of hard corals among inner, mid- and outer reefs. On inner reefs, with the exception of those in the Cairns sector, hard coral cover remained stable throughout the study (Fig. 4). In contrast, cover was extremely variable on mid-shelf sectors. In the Townsville and Whitsunday sectors, for example, cover increased for $4 \mathrm{yr}$, then declined in the fifth year. In the Swains sector, there was no clear temporal trend in coral cover. On outer shelf reefs, hard coral cover increased sharply on reefs in sectors at the lowest (Cooktown-Lizard) and highest (Capricorn-Bunker) latitudes, increased slightly in the Cairns and Townsville sectors, and remained stable in the Whitsunday and Swains sectors.

Fully nested ANOVAs showed that relatively little of the change in hard coral cover occurred among reefs and sites, with these factors accounting for only 14 and $8 \%$ of variation in the data set, respectively (Table 2 ).

Table 2. Summary of results of fully nested ANOVA analyses of mean annual change in cover of hard coral, algae and soft coral. Data were transformed to arc-sine values prior to analysis. The percentage of variation accounted for by each factor in the analysis is shown (\% var). Data sets from Swains reefs were excluded from analyses as sampling in this sector could not be stratified by shelf position

\begin{tabular}{|llrcccr|}
\hline Group & Effect & df & MS effect & $F$ & $p$ & $\%$ var \\
\hline Hard coral & & & & & & \\
& Locality & 12 & 0.0655 & 7.1267 & $<0.0001$ & 37 \\
& Reef & 28 & 0.0092 & 3.5086 & $<0.0001$ & 14 \\
& Site & 82 & 0.0026 & 2.0049 & $<0.0001$ & 8 \\
& Transect (error) & 492 & 0.0013 & & & 41 \\
Soft coral & & & & & & \\
& Locality & 12 & 0.0065 & 0.9893 & 0.4830 & $<1$ \\
& Reef & 28 & 0.0066 & 6.0388 & $<0.0001$ & 36 \\
& Site & 82 & 0.0011 & 2.0217 & $<0.0001$ & 10 \\
& Transect (error) & 492 & 0.0005 & & & 53 \\
& & & & & & \\
& Locality & 12 & 0.1325 & 6.8931 & $<0.0001$ & 43 \\
& Reef & 28 & 0.0192 & 4.3296 & $<0.0001$ & 18 \\
& Site & 82 & 0.0044 & 2.6955 & $<0.0001$ & 10 \\
& Transect (error) & 492 & 0.0016 & & & 30 \\
\hline
\end{tabular}


Inner

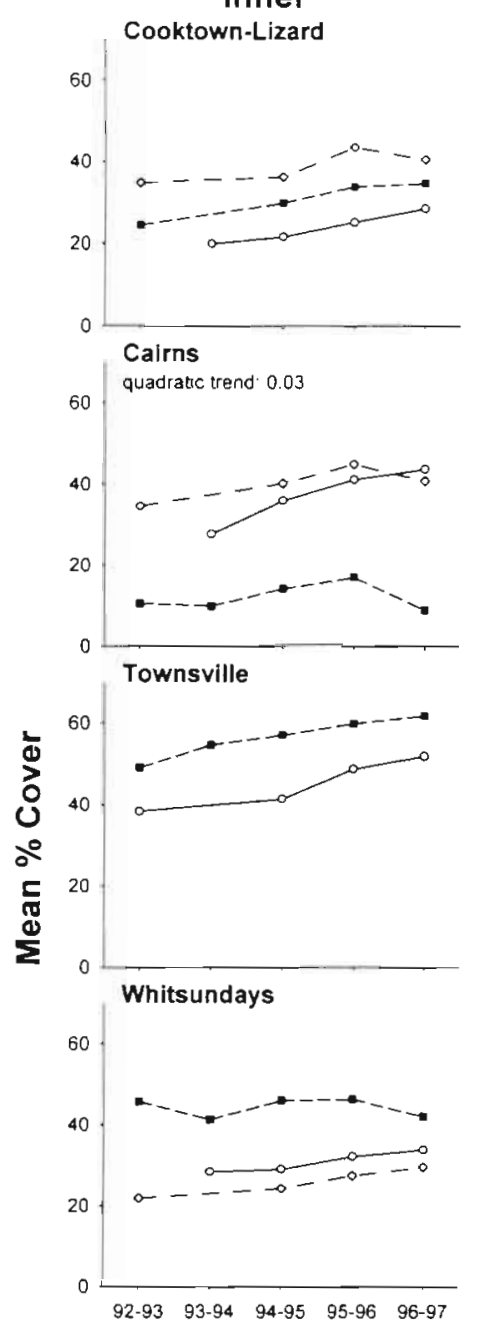

Mid-
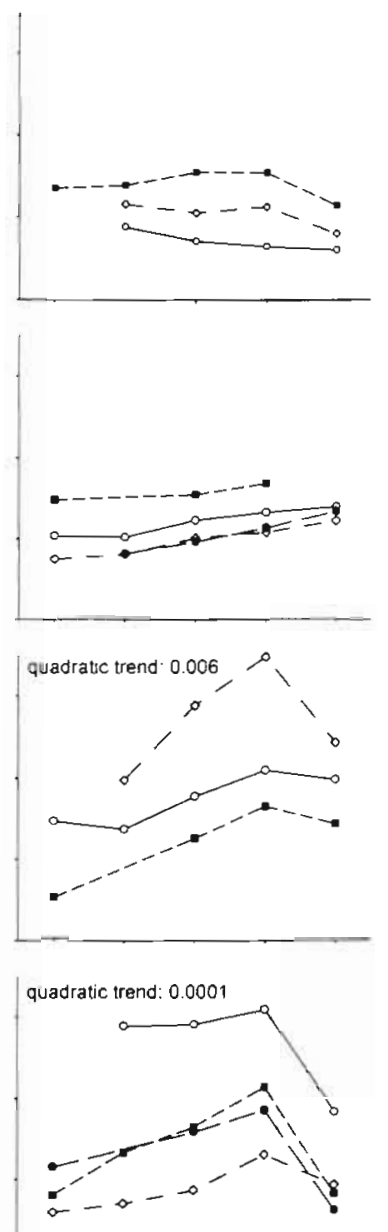

Swains

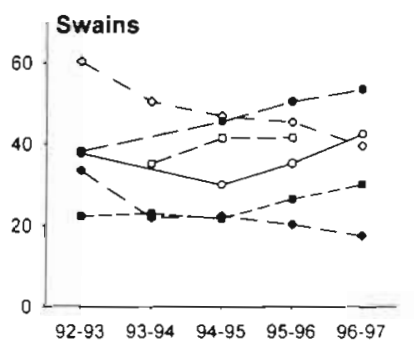

Outer

linear trend: 0.0001

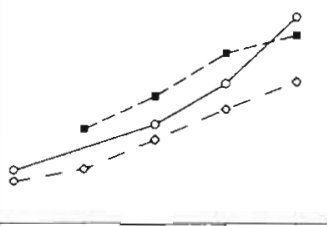

quadrauc trend 0.05

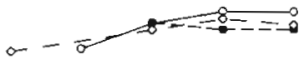

quadratic trend 0.05
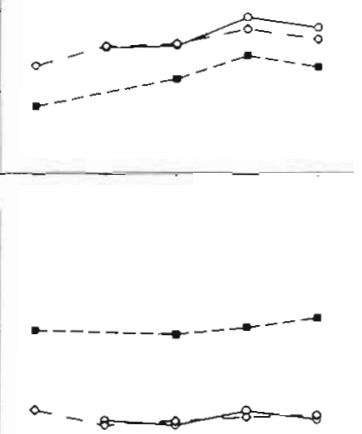

Capricorn Bunkers

Fig. 4. Temporal trends of mean percentage cover of hard corals on the northeast flanks of inner,

Year mid-and outer shelf reefs from 6 sectors of the GBR. Traces represent patterns on individual reefs within each locality, p-values are given where the mixed-model analysis detected a significant linear or quadratic trend in cover for a locality

In contrast, differences among localities accounted for $37 \%$ of variability. The remainder $(41 \%)$ was due to changes in cover at the scale of transects

Cover of soft corals remained stable in all but 2 of the 15 localities. Significant changes occurred on mid-

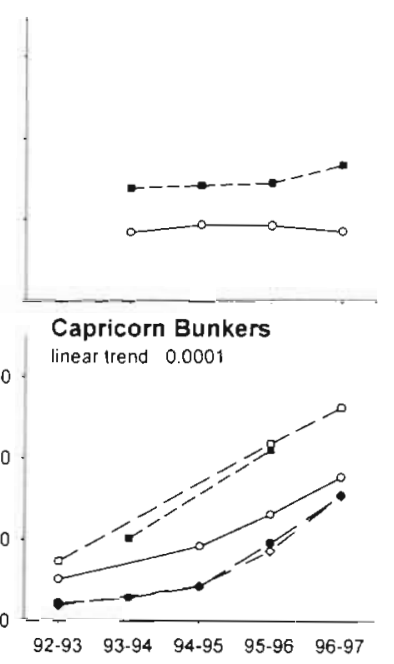
linear trend 0.0001

60

shelf reefs in the Whitsunday and on outer shelf reefs in the Capricorn-Bunker sectors (Fig. 5A). These were due to relatively large changes in cover that occurred on a single reef in each location. Less than $1 \%$ of the variation occurred at the scale of localities (Table 2). 


\section{A. Soft Corals}
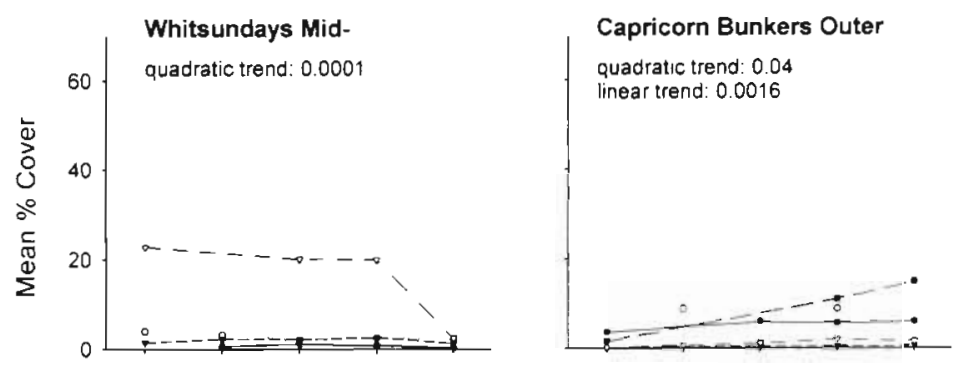

Fig. 5. (A) Temporal trends of mean percentage cover of soft corals on the northeast flanks of individual reefs within localities where significant changes in cover were recorded. B) Trends in cover of algae at localities where there were major changes in cover of hard corals (see Fig. 4). p-values are given where the mixed-model analysis detected significant linear or quadratic trends in cover at the scale of localities

\section{B. Algae}
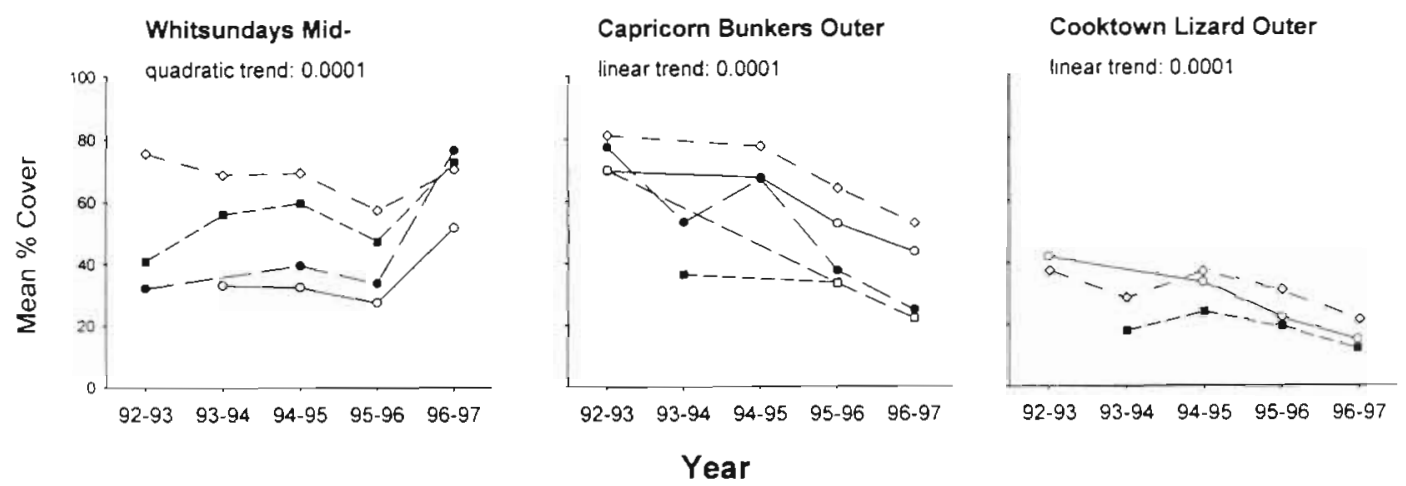

Changes in this group mostly occurred at the scales of reefs $(36 \%)$ and transects $(53 \%)$.

There were significant changes in the cover of algae during the study. In 6 localities, they were the opposite of changes that occurred in the cover of hard corals (Fig. 5B). The most dramatic changes in algal cover occurred in 3 localities where large changes in hard coral cover were also recorded. The ANOVA (Table 2) confirmed the importance of changes at this spatial scale, with the majority of variation due to differences occurring among localities (43\%).

\section{Spatial coherence of changes among reefs and sites}

The spatial coherence of changes in cover of hard corals at the scales of reef and site was also examined graphically, Average annual changes in cover were classified into 3 broad categories ('no change', $\leq 5 \%$ change; 'increase', >5\% increase; 'decrease', >5\% decline in cover) and plotted for each site at each reef (Fig. 6). These categories were chosen as a $5 \%$ increase or decrease in cover is the approximate lower limit of annual change in cover that can be detected by the video method at the scale of a single transect (Davidson 1998).

Temporal patterns tended to be consistent among reefs within a locality and among sites within a reef. For example, a strong general trend of increasing cover occurred on outer shelf reefs in the CooktownLizard sector where average annual increases of $>5 \%$ in hard coral cover were recorded at all of the 9 sites on the 3 reefs. Similarly, on outer shelf reefs in the Capricorn-Bunker sector, where cover of hard corals also increased, $>5 \%$ average annual increases occurred on all 4 reefs and at 9 of the 12 sites. In most sectors where there was no strong temporal trend in coral cover at the scale of localities, only very small average changes $(\leq 5 \%)$ in cover were recorded among reefs and sites within localities. Mid-shelf reefs in the Swains were an exception to this pattern, displaying a variety of changes among reefs and sites that ranged from $>5 \%$ average annual increases in coral cover at all sites on one reef, to $>5 \%$ average declines in cover at 2 of the 3 sites on another reef. Such differences probably reflect the presence of small populations of COTS on some of the reefs in this locality (Sweatman 1997).

Our study could identify few strong temporal trends in cover of soft corals at the scale of localities. This pattern was consistent among sites, with $>5 \%$ average annual changes in cover of soft corals detected at only 8 of the 147 sites sampled by the study.

For algae, approximately $33 \%$ of the sites sampled by the study displayed $>5 \%$ average annual changes. Changes among sites and reefs were consistent with those occurring at the scale of localities and tended to be the opposite of those occurring in cover of hard corals. 


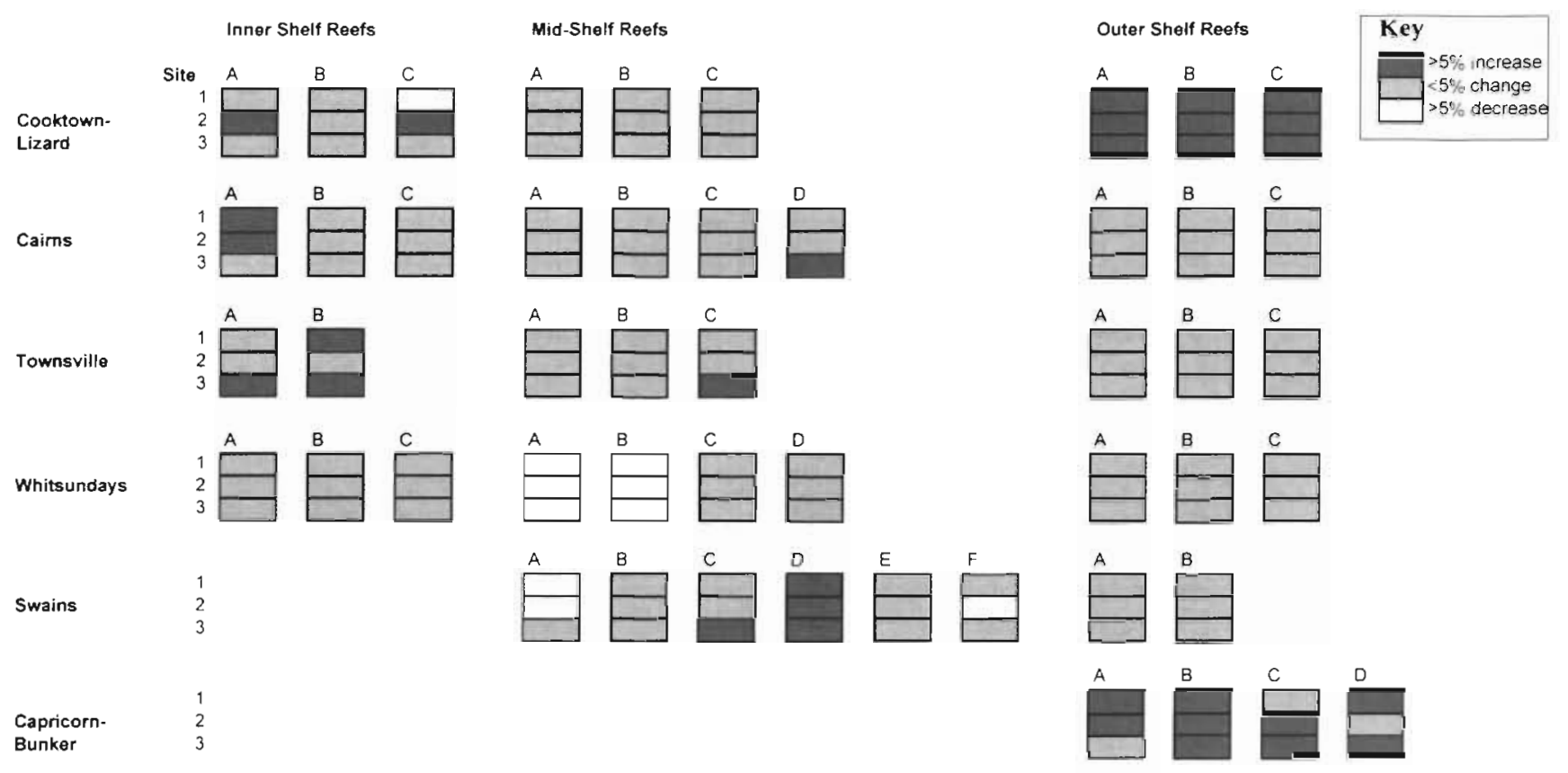

Fig. 6. Average annual changes in hard coral cover at sites and reefs in each locality sampled by the LTMP survey. Changes were grouped into 3 categories: $>5 \%$ average annual increase, $<5 \%$ average annual change and $>5 \%$ average annual decrease in cover

\section{Changes in cover of components of hard coral assemblages}

Hard coral assemblages were dominated by the genus Acropora on mid- and outer shelf reefs, where this family comprised 36 and $42 \%$ of cover, respectively. Within the Acropora, tabulate life-forms were most abundant on outer shelf reefs where they composed $14.4 \%$ of the cover of live coral. On mid-shelf reefs, this life-form accounted for $10.8 \%$ of coral cover, while on inner shelf reefs, it averaged only $3.1 \%$ Other Acropora life-forms displayed a similar pattern, averaging 27.4 and $25.3 \%$ of cover of live coral on outer and mid-shelf reefs respectively, but only $15.8 \%$ on inner shelf reefs.

Where there were strongly significant increases or declines in hard coral cover during the study, changes in component groups did not necessarily follow the overall trends (Fig. 7). On mid-shelf reefs in the Townsville sector, cover of tabulate Acropora varied more dramatically than other corals. The fluctuating pattern in cover of tabulate Acropora was due to rapid growth followed by the effects of storms. In contrast, on mid-shelf reefs in the Whitsunday sector, both nonAcropora and Acropora corals showed the same pattern of an increase followed by a decline in cover. Acropora and non-Acropora corals contributed to the striking trend of increasing cover on outer shelf reefs in the Cooktown-Lizard sector. There were small but significant increases in total cover of hard corals on outer reefs in the Cairns and Townsville sectors. These were largely due to the growth of tabulate Acropora, while other corals showed no significant changes in cover. In the Capricorn-Bunker sector there was a major increase in total cover of hard coral that was primarily due to the growth of tabulate Acropora. In this sector there were only small but significant increases in cover of other types of corals

\section{DISCUSSION}

Our results show that hard corals are the dominant and most dynamic component of the benthic assemblages on the northeast flanks of reefs on the GBR. Overall, cover of hard corals increased during the study, while cover of soft corais and algae remained static or declined slightly and contributed little to overall changes in benthic cover. These general trends were shown to be the net result of increases and decreases among localities distributed throughout the GBR.

It is clear that most of the declines in cover of hard coral were caused by discrete disturbances. In a separate component of the program (Oliver et al. 1995), we have documented the presence of populations of COTS affecting coral cover on a number of the study reefs. Moreover, the GBR is crossed on average by $\sim 2$ cyclones $\mathrm{yr}^{-1}$ (Poutinen et al. 1997), and there are latitudinal differences in cyclone strength and frequency that suggest there is a different life expectancy 


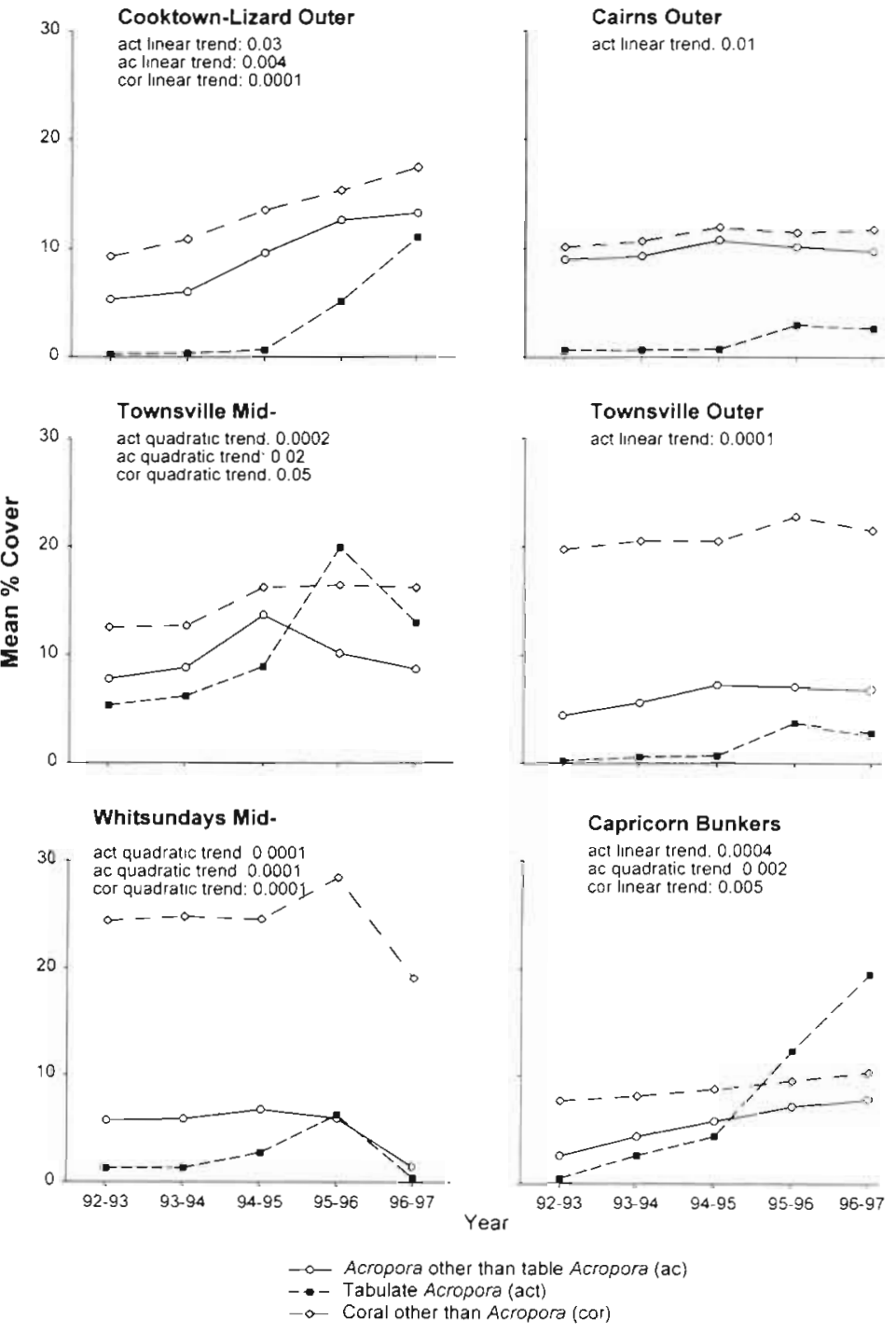

Fig. 7. Temporal trends of mean percentage cover of components of the hard coral assemblages in localities where there were major changes in total cover of hard corals (see Fig. 4). p-values are given where mixed-model analysis detected significant linear or quadratic trends in the component group

for corals in different localities (Massel \& Done 1993). In all cases, the major declines in coral cover recorded by our study coincided with the presence of COTS populations, or the passage of cyclones in the vicinity of reefs. Both disturbances cause moderate to catastrophic declines in hard coral and leave distinctive signatures: the former, standing dead skeletons (Moran 1986), the latter, varying degrees of physical damage (Done 1992c, Massel \& Done 1993). Disturbances were initially followed by an increase in algal cover.

We found no evidence of any persistent shift to assemblages of alyae or soft corals. High cover of algae appeared to be a transient stage associated with a reduction in cover of hard coral. Prolonged dominance by algae would require either failure of recruitment, high post-settlement mortality of hard corals, or both. These results support the conclusions of a recent review of 'long term' ( $>4 \mathrm{yr}$ ) studies of temporal patterns in coral assemblages by Connell (1997). In habitats where disturbance had removed coral cover, Connell found that a return to assemblages dominated by hard corals was the norm, provided that disturbance was an acute event. Lack of regrowth of hard corals and phase shifts to algal assemblages only occurred in the presence of chronic disturbance (Hughes 1994, Grigg 1995, Connell 1997). Our study reefs were clearly not chronically disturbed.

Much of the variability in temporal patterns among coral reef localities can be due to the differing disturbance histories of coral reefs (Connell 1978). On the GBR, 2 outbreaks of COTS have been recorded since the early 1960s (Moran 1986, Moran et al. 1988). During the more recent of these, COTS populations were recorded on 19 of the 52 survey reefs (Oliver et al. 1995). Reefs in the Cairns and Cooktown-Lizard sectors were also disturbed by Cyclone Ivor, which caused widespread damage to hard corals in 1990 (van Woesik et al. 1991, Done 1992c). In the Capricorn-Bunker sector, reefs were exposed to a disturbance event (probably storms), that reduced hard coral cover from $40-50 \%$ in $1987-88$ to $20-30 \%$ after 1990 (Oliver et al. 1995). Consequently, many survey reefs were at differing stages of recovery of hard coral assemblages when surveys began in 1992. Recovery from these disturbances probably accounts for the strong increases in hard coral cover on outer shelf reefs in the Cooktown-Lizard and Capricorn-Bunker sectors and on mid-shelf reefs in the Cairns sector. More recent events have also contributed to the variability in temporal patterns at this spatial scale. For example, the recent reduction in coral cover on mid-shelf reefs in the Whitsunday and Townsville sectors during the last year of the survey was probably due to the effect of Cyclone Justin, which caused widespread damage to hard corals on mid-shelf reefs in these sectors in March 1997.

While it is theoretically possible that frequent disturbance could decrease longer-term variability in cover of hard coral by preventing regrowth between events, this was not case in this study. The very low levels of coral cover that were recorded in some outer shelf localities in initial years of the survey were not maintained. Rather, corals in these localities showed strong increases in cover during the period of the survey that 
was attributable to both Acropora and non-Acropora corals. Thus, even in outer and mid-shelf localities, the intervals between disturbance events appear to have been sufficient to allow substantial regrowth of corals.

The study has shown that 1992 to 1997 were 'good years' for hard coral growth in 11 of the 15 locations (Fig. 4). The data set thus provides the basis for defining some benchmarks for performance for corals on NE slopes of GBR coral reefs. For example, on those reefs that showed a monotonically increasing trend in hard coral cover, the average annual rates of increase were 2.6, 3.8 and $4.3 \%$ on inner, mid- and outer reefs, respectively. These rates may be used in a management context to estimate 'time to recovery' to some target level of coral cover, 'all else being equal' (i.e. given good coral establishment and a period of uninterrupted increase in coral cover).

\section{CONCLUSION}

While this study showed considerable vanability in temporal patterns among localities, trends in cover of hard corals and algae tended to be consistent among reefs, sites and transects within a locality. This suggests that a single disturbance such as a cyclone or a COTS outbreak can be sufficiently widespread to affect most reefs and sites within any particular locality, here representing areas around 10 s of kilometres a side and separated from other localities by 10 s to 100 s of kilometres. At these scales, only occasionally will a single event influence reefs in more than 1 locality in the same year. Conversely, the relative uniformity of changes within localities suggests that we may have more confidence that a small number of reefs may be more representative of the locality than we might previously have expected.

Our study suggests that hard coral assemblages on the GBR may usefully be viewed as a mosaic of patches (Connell 1978, Borman \& Likens 1979). In such a model, the distribution, size and state of the various patches in the mosaic is determined by variability in severity and return times for disturbances among reefs at differing positions on the continental shelf and by the spatial extent of these disturbances. We recognise patches roughly equivalent in size to a locality, (approximately 15 to $100 \mathrm{~km}$ ), within which the reefs are at a similar stage of recovery. Since the total abundance of hard corals was increasing at the largest spatial scale (most of the GBR) the mosaic in total was in a 'non-steady state' (Baker 1989, Turner et al. 1993) for the period of the study. These ideas may be useful in developing indicators and benchmarks for 'the state of the GBR', a system that is naturally variable over many scales of time and space.
Acknowledgements. We wish to thank all members of the LTMP team who have assisted in the collection and analysis of data. We also thank the captains and crews of the RV 'Sirius', RV 'Harry Messel' and RV 'Lady Basten' for their help during the field work for this study. Kate Osborne, Paula Tomkins, Will Oxley, Andrew Heyward, Katharina Fabricius and Glen De'ath provided valuable comments on earlier versions of the manuscript. This work is a contribution from the CRC Reef Research Centre and is AIMS publication no 968

\section{LITERATURE CITED}

Baker WL (1989) Landscape ecology and nature reserve design in the Boundary Waters Canoe Area, Minnesota. Ecology 70:23-35

Benayahu Y, Loya Y (1981) Competition for space among coral-reef sessile organisms at Eilat, Red Sea. Bull Mar Sci $31: 514-522$

Borman FH, Likens GE (1979) Patterns and processes in a forested ecosystem. Springer-Verlag, New York

Bythell JC, Bythell M, Gladfelter EH (1993) Initıal results of a long-term coral reef monitoring program: impact of Hurricane Hugo at Buck Island Reef National Monument, St. Croix, U.S. Virgin Islands. J Exp Mar Biol Ecol 172:171-183

Carleton JH, Done TJ (1995) Quantitative video sampling of coral reef benthos: large scale application. Coral Reefs 14 $35-46$

Christie CA, Bass DK, Neale SJ, Osborne K, Oxley WG (1996) Surveys of sessile benthic communities using the video technique. Long Term Monitoring of the Great Barrier Reef, Standard Operational Procedure No. 2, Australian Institute of Marine Science, Townsville, Queensland, Australia (accessed: February 16, 2000); available at www. aims.gov.au/reef-monitoring

Connell JH (1978) Diversity in tropical rainforests and coral reefs. Science 199:1302-1310

Connell JH (1997) Disturbance and recovery of coral communities. Coral Reefs 16(Suppl):S101-S113

Connell JH, Hughes TP, Wallace CC (1998) A 30-year study of coral community dynamics: influence of disturbance and recruitment on abundance, at several scales of space and time. Ecol Monogr 67:461-488

Davidson J (1998) Optimising the use of a video transect technique for the monitoring and rapid ecological assessment of tropical benthic communities. MSc thesis, James Cook University, Townsville

Dollar SJ (1982) Wave stress and coral community structure in Hawaii. Coral Reefs 1:71-81

Dollar SJ, Tribble GW (1993) Recurrent storm disturbance and recovery: a long-term study of coral communities in Hawaii. Coral Reefs 12:223-233

Done TJ (1982) Patterns in the distribution of coral communities across the Central Great Barrier Reef. Coral Reefs 1:95-107

Done TJ (1992a) Phase shifts in coral reef communities and their ecological significance. Hydrobiologia 247:121-132

Done TJ (1992b) Constancy and change in some Great Barrier Reef coral communities: 1980-1990. Am Zool 32:655-662

Done TJ (1992c) Effects of tropical cyclone waves on ecological and geomorphological structures on the Great Barrier Reef. Cont Shelf Res 12:859-872

Done TJ (1997) Decadal changes in reef-building communities: implications for reef growth and monitoring programs. Proc 8th Int Coral Reef Symp, Panama 1:411-416

Done TJ, Osborne K, Navin KF (1988) Recovery of corals post Acanthaster: progress and prospects. Proc 6th Int Coral Reef Symp, Townsville 2:137-142 
Edmunds PJ, Bruno JF (1996) The importance of sampling scale in ecology: kilometre-wide variation in coral reef communities. Mar Ecol Prog Ser 143:165-171

Endean R, Cameron AM, DeVantier LM (1988) Acanthaster planci predation on massive corals: the myth of rapid recovery of devastated reefs. Proc 6th Int Coral Reef Symp $2: 143-148$

Glynn PW (1993) Coral reef bleaching: ecological perspectives Coral Reefs 12:1-17

Grigg RW (1995) Coral reefs in an urban embayment in Hawaii: a complex case history controlled by natural and anthropogenic stress. Coral Reefs 14:253-266

Hughes TP (1994) Catastrophes, phase shifts, and large-scale degradation of a Caribbean coral reef. Science 265: $1547-1551$

Hunter CL, Evans CW (1995) Coral reefs in Kaneohe Bay, Hawaii: two centuries of western influence and two decades of data. Bull Mar Sci 57:501-515

Massel SR, Done TJ (1993) Effects of cyclone waves on massive coral assemblages on the Great Barrier Reef: meteorology, hydrodynamics and demography. Coral Reefs 12: $153-166$

McCullagh P, Nelder JA (1989) Generalized linear models, 2nd edn. Chapman \& Hall, London

Moran PJ (1986) The Acanthaster phenomenon. Oceanogr Mar Biol 24:379-480

Moran PJ, Bradbury RH, Reichelt RE (1988) Distribution of the crown-of-thorns starfish (Acanthaster planci) along the Great Barrier Reef: 1985-1986. Coral Reefs 7:125-137

Editorial responsibility: Daniel Alongi (Contributing Editor), Townsville, Queensiand, Australia
Oliver J, De'ath G, Done T, Williams D, Furnas M, Moran P (1995) Long-term monitoring of the Great Barrier Reef. Status Report No. 1, Australian Institute of Marine Science, Townsville, Queensland, Australia. laccessed: February 16, 2000); available at www.aims.gov.au/reefmonitoring

Poutinen ML, Done TJ, Skelly W (1997) An atlas of tropical cyclones in the GBR region 1969-1997 CRC Reef Research Centre Technical Report No 19, Townsville CRC Reef Research Centre, Townsville

Sweatman H (1997) Long-term monitoring of the Great Barrier Reef. Status Report No. 2, Australian Institute of Marine Science, Townsville, Queensland, Australia. (accessed: February 16, 2000); available at www.aims.gov. $\mathrm{au} / \mathrm{reef}$-monitoring

Sweatman $H$, Bass D Cheal A, Coleman G, Miller I, Ninio R, Osborne K, Oxley W, Ryan D, Thompson A, Tomkins P (1998) Long-term monitoring of the Great Barrier Reef. Status Report No. 3, Australian Institute of Marine Science, Townsville, Queensland, Australia. (accessed: February 16, 2000); available at www.aims.gov.au/reefmonitoring

Turner MG, Romme WH, Gardner RH, O'Neill RV, Kratz TK (1993) A revised concept of landscape equilibrium: disturbance and stability on scaled landscapes. Landscape Ecol 8:213-227

van Woesik R, Ayling AM, Mapstone B (1991) Impact of tropical cyclone 'Ivor' on the Great Barrier Reef, Australia. J Coast Res 7:551-558

Submitted: January 4, 1999, Accepted: August 27, 1999 Proofs received from author(s): February 21, 2000 